\title{
The Use of Study Anxiety Intervention in Reducing Anxiety to Improve Academic Performance among University Students
}

\author{
Prima Vitasari \\ Faculty of Technology Management, Universiti Malaysia Pahang \\ Lebuh Raya Tun Razak, Gambang 26300, Pahang, Malaysia \\ Tel: 60-1-7706-7278Ｅ-mail: primavitasari@yahoo.com \\ Muhammad Nubli Abdul Wahab \\ Center of Modern Language and Human Science, Universiti Malaysia Pahang \\ Lebuh Raya Tun Razak, Gambang 26300, Pahang, Malaysia \\ Tel: 60-9549-302Ｅ-mail: nubli@ump.edu.my \\ Ahmad Othman \\ Faculty of Technology Management, Universiti Malaysia Pahang \\ Lebuh Raya Tun Razak, Gambang 26300, Pahang, Malaysia \\ Tel: 60-9549-2166 E-mail: ahmadbo@ump.edu.my \\ Muhammad Ghani Awang \\ Center of Modern Language and Human Science, Universiti Malaysia Pahang \\ Lebuh Raya Tun Razak, Gambang 26300, Pahang, Malaysia \\ Tel: 60-9549-302Ｅ-mail: ghani@ump.edu.my
}

This work was supported under the research grant No. Vote 070144, Universiti Malaysia Pahang, Malaysia.

\begin{abstract}
Anxiety is one of the wide varieties of emotional and behaviour disorders, it is a major predictor for low academic performance among students. To this, anxiety should be taken seriously. Students need some form of intervention to reduce anxiety and assist in improving academic performance. Study anxiety intervention is designed to help students handle the problem of anxiety while studying. In this paper, a study anxiety intervention program is designed to manage students study anxiety in order to improve academic performance among students is proposed. Twelve healthy students are selected for this research, from five engineering faculties at Universiti Malaysia Pahang. They are divided into two equal groups which the experiment group and the control group, each are six participants. The training runs on duration of six sessions with the experiment groups receiving full training and no training for the control groups. The results show that the experiment groups performed better in coping anxiety levels as well as increasing academic performance compared to the control groups. Based on these results, study anxiety intervention can be concluded as an effective program to improve academic performance among university students. Therefore, the participants should practice these techniques effectively to be able in study anxiety coping to enhance their academic performance.
\end{abstract}

Keywords: Study Anxiety Intervention, Academic Performance, Student

\section{Introduction}

Students have a great deal of self control to balance the two necessary conditions posited and consequently move forward at least in term of academic performance or success in study. Students have an average intelligence but they differ in brain function and this can cause students to perform poorly in their studies (Cooley, 2007). One of 
the factors which influence the students' academic performance is anxiety disorder. This occurs when the student are encountering anxiety disorder in process of study (Heather \& April, 2008; Soler, 2005; McCraty, 2007). In fact, $75 \%$ of all individuals with anxiety disorders will experience it during study at university (Bolden, 2008; Margarita, 2008). Mostly, university students are suffer to some degree with some level of anxiety. Speilberger has defined anxiety as the subjective feeling of tension, apprehension, nervousness, and worry associated with arousal of the nervous system (Feryal, 2007). The anxiety's psychological symptoms among students include feeling nervous before attending classes, panicking, going blank during a test, feeling helpless while doing assignments, or lack of interest shown in subjects which are considered difficult whereas the physiological symptoms include sweaty palms, racing heartbeat, or an upset stomach (Ruffin, 2007). Students with anxiety disorder mostly attend their classes but choose to display a passive attitude because of lack of interest in learning the subject. The anxiety level creates normal life difficult for students and relaxation is nearly impossible, for others the anxiety interferes with everyday functioning like studies, their daily activities, and social life among students. Anxiety is one of the wide varieties of emotional behaviour (Rachel \& Chidsey, 2005), in classroom setting anxiety disorders may manifest in students' behaviours. Anxiety is a major predictor of academic performance (McCraty, 2007; McCraty, Dana, Mike, Pam \& Stephen, 2000) and various studies have demonstrated that it has a detrimental effect. Little is known on the possible association between high level of anxiety and low academic performance among students. Researches have been looking at the correlation of anxiety sources and the effect of academic performance. Students with higher level of anxiety will achieve a lower academic performance (McCraty, 2007; Heather \& April, 2008) and greater anxiety would be associated with poorer academic achievement (Luigi, Francesca, Maria, Eleonora, Valentina \& Benedetto, 2007). There are many studies done on anxiety level but not many studies are done to design intervention program with tools to reduce the anxiety level and students academic performance. Generally, high level of anxiety is more closely associated with lower performance in low ability students (Sena, et. al, 2007). High level of anxiety reduces working memory, impairs concentration, and reasoning (Cassady, 2001). The prevalence of anxiety among university students has been acknowledged by students and educators. However, study anxiety is a real phenomena, hence it is important ton have an understanding of study anxiety and particularly able to determine the sources of anxiety and be able to handle it. The research has designed an intervention program to cope of study anxiety in improving academic performance. Students learned the intervention techniques and practiced these techniques by using biofeedback equipment to cope the anxiety during study.

\section{Definition of Anxiety}

Anxiety is one's response to stress. These symptoms can be psychological physical or environmental challenges. There are various forms of anxiety include excessive worrying, a sense of fear, restlessness, overly emotional responses, and negative thinking. For some people, who are anxious may appear calm but the brain seems to be never quiet like cannot stop thinking. This situation can turn so bad and may interrupt the quality of life. All of the anxiety disorders are defined by the dual characteristic of physiologic hyper arousal and excessive emotional fear (Brauer, 1999). Anxiety is one of the psychophysiology difficulties (Roger, 2001). According to Sarason that anxiety is a basic human emotion consisting of fear and uncertainty that typically appears when an individual perceives an event as being a threat to the ego or self esteem (Harris \& Coy, 2003). In the conceptualization, individuals with high levels of anxiety generally hold heightened levels of trait anxiety. State anxiety is apprehension experienced at a particular period of time, where as trait anxiety refers to relatively stable individual differences that characterize people's anxiety (AltMD, 2008). This combinatory relationship can lead to feelings of anxiety that interferes with performance through blocks of utilization, attention resources, or more cognitive interference from the worries and fears induced by anxiety. A certain level of anxiety has been found to be a facilitative tool for an individual to perform effectively.

\section{Intervention to Regulate Study Anxiety}

The intervention appears to play a useful role in treatment of study anxiety. It is not only effective by providing the right techniques but also adds a significant component to the benefit of the training. These techniques are designed to prevent the development of intervention by increasing study anxiety resilience and promoting positive coping skills to improve academic performance. The materials of study anxiety intervention are adopted from existing techniques and skill related with this field. Study Anxiety Intervention (SAI) describes how to assist students who have low academic performance and high anxiety level, and provide an overview of the intervention by using biofeedback training. Intervention represents an important and necessary step for the benefit of students, university, and communities at large. Adequate academic services and educational intervention may assist student in developing and maintaining a positive self-image, thus decreasing risk of developing emotional problems (Soler, 2005). To reduce anxiety, researchers used breathing therapy as well 
relaxation. Breath regulation can be a very important self control skill to reduce anxiety. The study anxiety interventions included in the biofeedback training can be classified into module intervention and protocol techniques. By practicing the intervention techniques, students learn how to identify the unpleasant symptoms that appear with study anxiety and replace them with more relaxed feelings. The intervention is expected to expedite anxiety reduction and also positive adaptive attitude associated to each of the five study anxiety sources. In other words, the SAI can contribute significantly to overall anxiety-reduction benefits.

\section{Biofeedback for Students}

Anxiety attacks are very real to the person having experienced one and can paralyze someone from doing even the simplest of daily tasks. All of anxiety disorders are defined by the dual characteristic of physiological hyper arousal and excessive emotional fear. Anxiety is mediated by the Sympathetic Nervous System (SNS), when the SNS is activated of heart rate and respiration. Biofeedback is one of most useful adjuncts in treating physiological hyper arousal both episodic and chronic seen in anxiety disorder (McCraty, Dana, Mike, Pam \& Stephen, 2000). Yucha and Gilbert as stated in (Brauer, 1999), reported that randomized studies have shown biofeedback to be superior to other relaxation and self control methods for reducing anxiety. One way of anxiety disorders have been able to relieve symptoms is through biofeedback therapy. Biofeedback or applied psycho physiological feedback is a subject-guided treatment that teaches an individual to control muscle tension, pain, body temperature, brain waves, and other bodily functions and processes through breathing retraining, relaxation, visualization, and other cognitive control techniques (Soler, 2005). Biofeedback operates on the techniques in intervention that behaviours or involuntary responses can be controlled when subjects are conditioned to respond of physical changes in the bodies, biofeedback works like a mirror. The general principle that biofeedback could be used to teach arousal reduction, which should benefit the anxious, over aroused individual. Biofeedback assisted breathing retraining and muscle relaxation can be helpful in providing a motivational experience. As a result of this students will be able to reduce their anxiety. The researchers found that the biofeedback group had significantly lower post-test states and trait anxiety (AAPB, 2008). The biofeedback training used to help students prepare themselves mentally and physically for anxiety in studying process. Biofeedback training is part of behavioural treatment, like using relaxation techniques to treat the negative behaviour. Randomized biofeedback clinical trials have found that biofeedback reduces anxiety as much as popular relaxation procedures (Martin, 2008). Students use these techniques to manage study anxiety apprehension. This helps students to prepare for improve academic performance and reduce anxiety level related during their studies.

\section{Method}

This research uses randomized control trial with pre post test to collect data. The participants assign random for both of groups. The results are comparing between pre and post test among groups. The training material designed of study anxiety coping to improve academic performance. Many skills and techniques are available to cope study anxiety in enhance academic performance among students such breathing retraining, relaxation, study skill, and study anxiety coping skill.

\subsection{Participants}

The participants are engineering students from five faculties at Universiti Malaysia Pahang (UMP). The experiment involved twelve students who were assigned randomly into the experiment and the control groups. Students who are participants in the experiment group should posses these two criteria that are having a high anxiety level (state trait anxiety score $\leq 85$ ) and low academic performance (grade point average $\leq 2.50$ ). The participants did not participate voluntary, but who were rewarded with a token.

\subsection{Instrument}

The research used State Trait Anxiety Inventory (STAI) introduced by Spielberger (1983), a questionnaire designed to measure anxiety levels, stress sweeper biofeedback device for physiological assessment, and to measure students' academic performance, Grade Point Average (GPA) was used The instruments were consistent with the reliability and validity test.

\subsection{Procedure}

Twelve UMP's students participated in this research which was conducted over duration of six sessions of training. The experiment group received full training and no training was done for the control groups. For the first session participants received for a pre test which encompasses answering the STAI questionnaires and a physiological assessment was done to measure anxiety level. Post test was conducted in the last sessions with the same test with the pre test. Participants learned regarding the intervention techniques and applying the techniques by using biofeedback device. The biofeedback device guides participants to practice the techniques in 
regulate heart beat and respiration in term of reducing study anxiety disorders. The participants should be practicing the techniques out of training to get effective benefit.

\subsection{Data analysis}

To analyze data univariate ANOVA was used to compare means of STAI scores and GPA between pre and post test of two groups. Comparison of physiological assessment was also conducted between pre and post test for both of these groups.

\section{Result and Discussion}

\subsection{Pre and Post Test Results}

The results show that the significant difference of pre and post tests between the experiment and the control groups. STAI scores is significant on level .024 with $\mathrm{p} \leq .05$ and GPA scores is significant on level .05 with $\mathrm{p}$ $\leq .05$ between these groups. Table 1 and 2 showed the significant test of anxiety level, and GPA. The training was conducted along six sessions during a short semester. One of the participants in the experiment group reduced his anxiety level in score 168/high level to score 74/low level. Male students performed better than those female students during the training. Figure 1 shows the reducing anxiety level between pre and post test. Meanwhile, Figure 2 shows the difference between pre and post test of academic performance.

$<<$ INSERT TABLE $1>>$

$<<$ INSERT TABLE $2>>$

$<<$ INSERT FIGURE $1>>$

$<<$ INSERT FIGURE 2>>

\subsection{Physiological Assessment}

The results show that there is a difference/gap of heart rate and respiration in pre and post test between the experiment group and the control group. It is calculated in one minute both on heart rate and respiration. Average of 70 beats/minute for heart rate and 6-12 breath/minute. Figure 4 and 5 showed the differences between beat/minute and breath/minute in an experiment group. Subjects' breathing in $21 \mathrm{breath} /$ minute and after learned the techniques to reduce anxiety he can breathe at 7 breath/minute. The Performance on heart beat for pre test in level 79 beat/minute to post test in level 73 beat/minute. The red wave's shows respiration calculates per-minute along 5 minute recording. Whereas, green waves shows heart beat which calculates per-minute along 5 minute recording.

$<<$ INSERT FIGURE 3 $>>$

$<<$ INSERT FIGURE $4>>$

$<<$ INSERT FIGURE $5>>$

$<<$ INSERT FIGURE 6>>

$<<$ INSERT FIGURE 7 $>>$

$<<$ INSERT FIGURE $8>>$

Based on Figures 5, 6, 7 and 8, it shows that students achieve high anxiety level in pre test or baseline. Higher anxiety indicates students can not perform well in their study. They feel lack of confidence, shy, passive, introvert, do not open up their minds, and these created low personal quality. Study anxiety intervention (SAI) aim was to teach students to be a calm person. It is necessary for students especially during their study or working on a task in the future. Meanwhile, the post test results show that students achieved low anxiety level; it reduced anxiety to $50 \%$. After the training, students felt more confident, in coping study anxiety, and were able to improve their academic performance.

\section{Conclusion}

Researchers have found that the biofeedback training is an effective technique in reducing psycho-physiological disorders to peak performance in any sites. Nowadays, biofeedback training is an effective program to reduce study anxiety and in improving academic performance among students in university. In this paper, we have proposed the biofeedback training to manage study anxiety in order to improve the academic performance among students. The results show that the experiment group was able in reducing anxiety level and improving their academic performance than that the control groups. The training required more than six sessions to reach the intensive level in students mastering techniques to reduce study anxiety and improving academic 
performance. Study anxiety intervention is not only effective for university students but also for students in any level, however the study is proposed for conducted research among high school students.

\section{References}

AAPB. (2008). Anxiety. Association for Applied Psychophysiology and Biofeedback.

AltMD. (2008). Control Anxiety with Biofeedback. [Online] Available: http:/www.altmd.com/Articles/Control-Anxiety-with-Biofeedback (July 6, 2008).

Bolden. (2008). Anxiety Disorders among College Students. [Online] Available: http://www.livestrong.com/health-article/anxiety-disorder-among-college-students_9dd271b9-ca2f-2e0e-28eb-a $82228 \mathrm{bc} 69 \mathrm{bd} /$ (May 20, 2009)

Brauer, A. (1999). Biofeedback and Anxiety. Psychiatric Times, Vol. 16, No. 2, 1-2.

Cassady, J.C. (2004). The Influence of Cognitive Test Anxiety across the Learning-Testing Cycle. Elsevier, Vol 14, No. 6, 569-592.

Cooley, M.L. (2007). Teaching Kid with Mental Health and Learning Disorders in the Regular Classroom: How to Recognize, Understand, and Help Challenged and Challenging Student Succeed. Free Spirit Publishing.

Feryal, C. (2007). Foreign Language Anxiety. Iranian Journal of Language Studies, Vol. 1, No 2, $133-144$.

Hamilton Health Sciences. (2006). Anxiety Disorder. McMaster University Medical Centre, Ontario, Canada.

Harris, H. L., \& Coy, D. R. (2003). Helping Students Cope with Test Anxiety. ERIC Counseling and Student Services Clearing House.

Heather, L. V., and April, L. C. (2008). The Relationship between Test Anxiety and Academic Performance. [Online] Available: http://clearinghouse.missouriwestern.edu/manuscripts/333.php (January 10, 2008)

Luigi, M., Francesca, D., Maria, D.S., Eleonora, P., Valentina, G.D., and Benedetto, V. (2007). The Role of Anxiety Symptoms in School Performance in A Community Sample of Children and Adolescents. BMC Public Health. 2007; 7: 347. Doi: 10.1186/1471-2458-7-347.

Margarita, T. (2008). Depression and Anxiety among College Students. Psych Central, 1-2. [Online] Available: http://psychcentral.com/lib/2008/depression-and-anxiety-among-college-students/ (September 10, 2008)

Martin, B. (2006). Strategies to Reduce Anxiety and Stress. PsychCentral. [Online] Available: http://psychcentral.com/lib/2006/strategies-to-reduce-anxiety-and-stress/(July 12, 2008)

McCraty, R. (2007). When Anxiety Causes Your Brain to Jam Use Your Heart. Institute of Heart Math.

McCraty, R., Dana, T., Mike, A., Pam, A., and Stephen, J. (2000). Improving Test-Taking Skills and Academic Performance in High School Students Using Heart Math Learning Enhancement Tools. Institute of Heart Math.

Rachel, B. and Chidsey. (2005). Assessment for Intervention: A Problem Solving Approach. The Guilford Press.

Roger, J.C. (2001). The Impact of Thought Field Therapy on Heart Rate Variability (HRV). Journal of Clinical Psychology, 1-3.

Ruffin, P. (2007). A Real Fear: It's More Than Stage Fright Math Anxiety can Derail Academic or Professional Success. But Some Scholars are Working to Help Students Get Over It. [Online] Available: http://diverseeducation.com/article/7085/1.php (January 10, 2008)

Sena, W., Lowe, P. and Lu, S. (2007). Significant Predictors of Test Anxiety among Students with and without Learning Disabilities. Journal of Learning Disabilities, Vol. 40, No. 4, 360-376.

Soler, K. U. (2005). The Relation among Depression, Anxiety, Memory, and Attention in a Sample of College Students with Learning Difficulties. Ph.D. Dissertation, Department of Psychology, Carlos Albizu University, $1-77$.

Spielberger. (1983). State Trait Anxiety Inventory. Mind Garden.

Table 1. Significant Test of Anxiety Level

\begin{tabular}{|l|c|c|c|c|c|}
\hline \multicolumn{1}{|c|}{ STAI } & Mean & std & df & F & Sig \\
\hline pre & 90.33 & 20.52 & & & \\
\hline post & 59.00 & 10.70 & & & \\
\hline Pre-post & & & 1 & 3.93 & 0.02 \\
\hline
\end{tabular}

Table 2. Significant Test of GPA

\begin{tabular}{|l|c|c|c|c|c|}
\hline \multicolumn{1}{|c|}{ GPA } & Mean & std & df & F & Sig \\
\hline pre & 2.28 & 0.44 & & & \\
\hline post & 2.80 & 0.36 & & & \\
\hline Pre-post & & & 1 & 4.96 & 0.05 \\
\hline
\end{tabular}




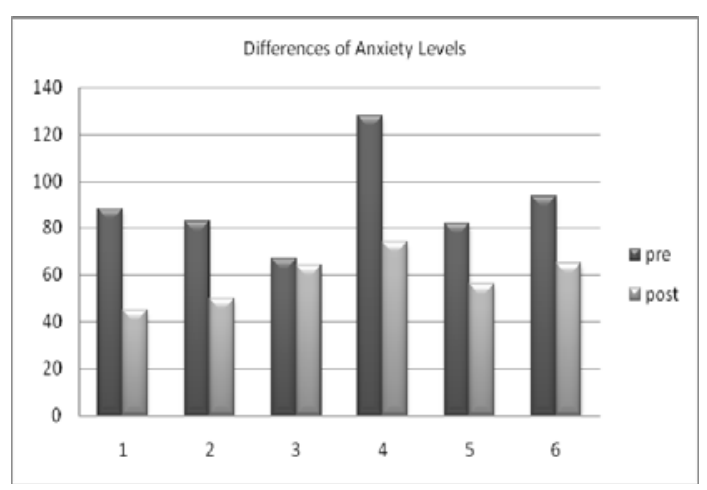

Figure 1. Anxiety Level

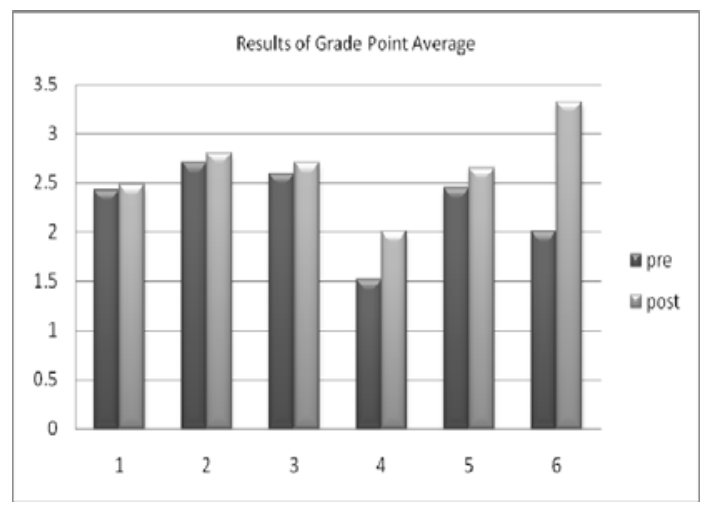

Figure 2. Academic Performance

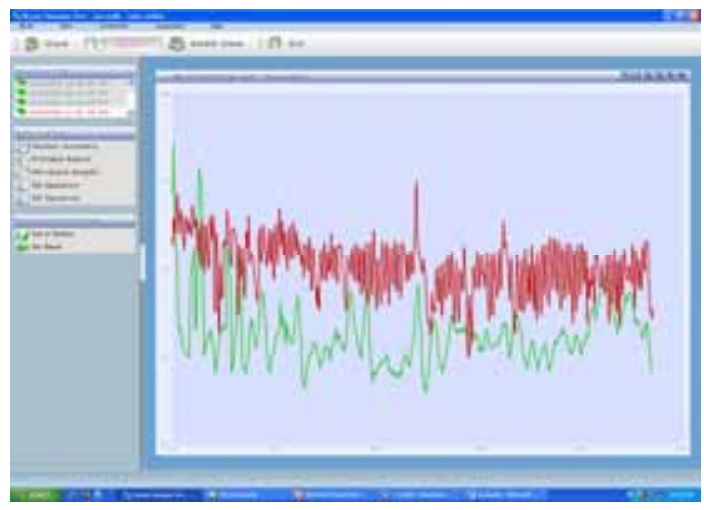

Figure 3. Pre Test of Heart Beat's Wave and Respiration's Wave

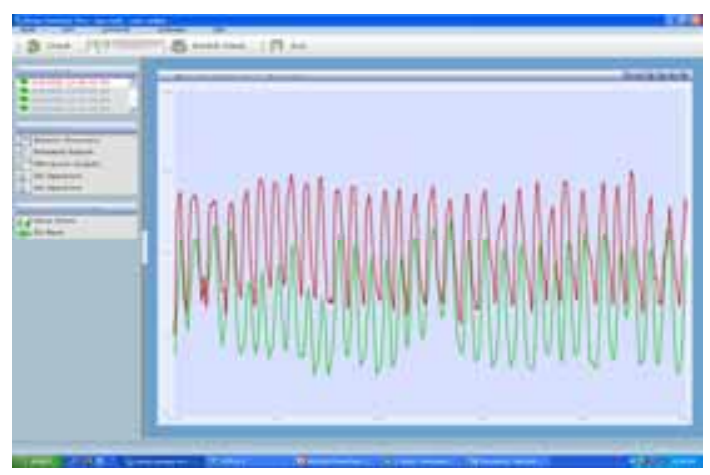

Figure 4. Post Test of Heart Rate's Wave and Respirations' Wave 


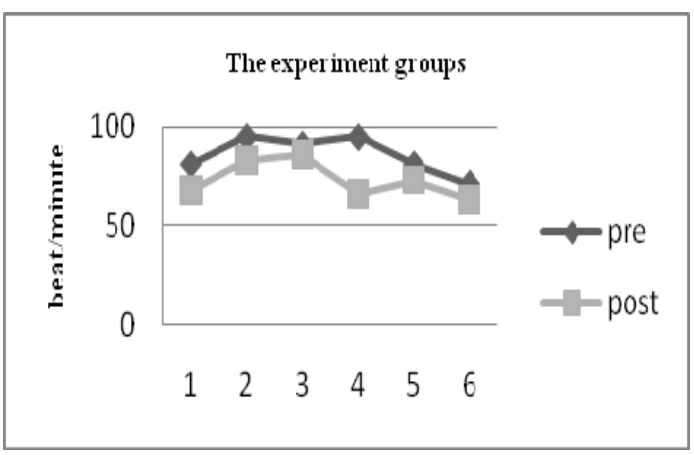

Figure 5. Pre and Post Tests of Heart Rate Assessment of Experiment Groups

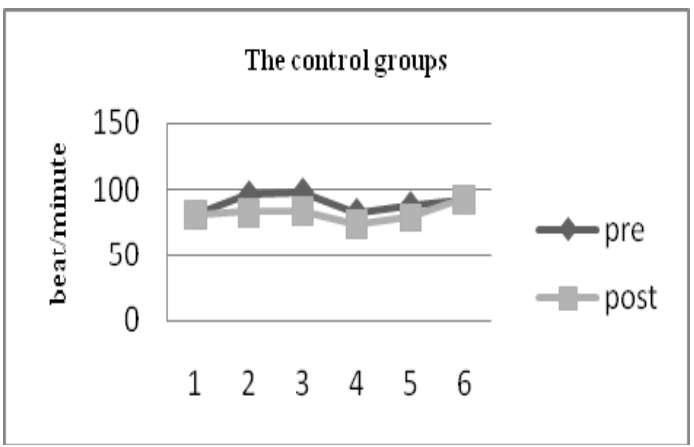

Figure 6. Pre and Post Tests of Heart Rate Assessment of Control Groups

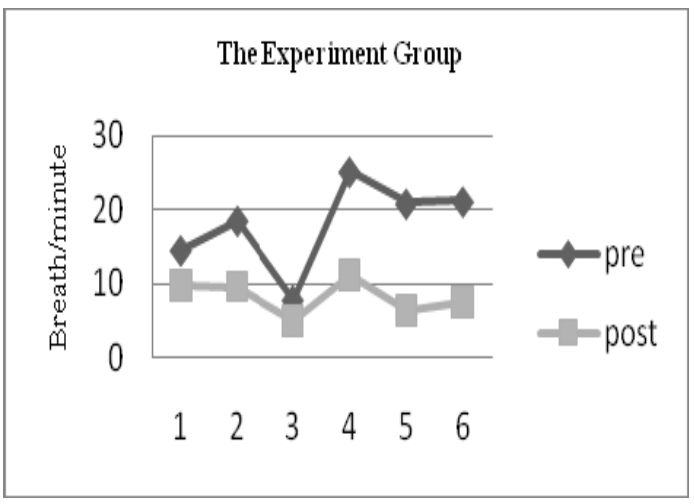

Figure 7. Pre and Post Test of Respiration Assessment of Experiment Groups

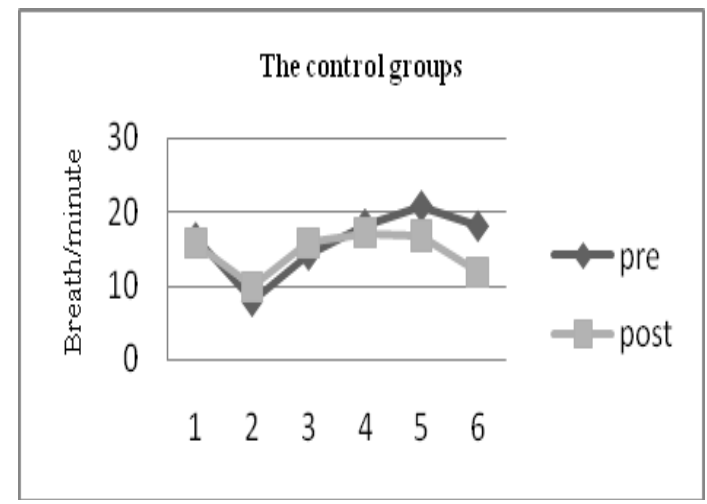

Figure 8. Pre and Post Tests of Respiration Assessment of Control Groups 